\title{
Estimation of Serum Copper and Zinc in Patients of Oral Submucous Fibrosis in Rural Population
}

\author{
Alka Hande ${ }^{1}$, Anand V Bansod ${ }^{2}$, Akhilesh G Agrawal ${ }^{3}$, Amol Gadbail ${ }^{4}$, Amit M Reche ${ }^{5}$
}

\begin{abstract}
Aim: To estimate the serum levels of copper (Cu) and zinc ( $\mathrm{Zn}$ ) in oral submucous fibrosis (OSMF) patients residing in the rural area. Materials and methods: The current study included 100 participants after receiving their written consent. The participants were broadly divided into group I (OSMF patients) and group II (Control), comprised of 70 and 30 individuals, respectively. The participants in group I were further categorized into three groups based on their clinical severity into group IA, group IB, and group IC corresponding to clinical stage I, stage II, and stage III OSMF, respectively. Intravenous blood was collected under a sterile environment in the plane bulb. Serum was separated and samples were stored at $-40^{\circ} \mathrm{C}$ until use. The samples were returned to room temperature and serum $\mathrm{Cu}$ and $\mathrm{Zn}$ levels were estimated by a calorimetric test using Dibromo-PAESA method described in the kit manufactured by Centronic $\mathrm{GmbH}$.

Results: There were 30 participants in group IA, 25 participants in group IB, and 15 participants in group IC. Serum Cu level was significantly increased in all OSMF patients (mean $=195.305 \mu \mathrm{g} / \mathrm{dL}$ ) in comparison with the control group and there was an increase in serum Cu level with an increase in the disease severity. Zinc level was decreased with a mean value of $80.12 \mu \mathrm{g} / \mathrm{dL}$ in comparison with the control group. Besides, the value decreased with an increased disease severity.

Conclusion: This study reveals that these trace elements are involved in the pathophysiology of OSMF. Serum Cu and Zn levels can be used as a diagnostic tool for the early diagnosis of OSMF.

Clinical significance: Serum Cu and Zn can be used as a marker to assess the OSMF disease severity. Being an important entity in the pathogenic mechanism of OSMF, their estimation may prove to be useful to dental surgeons in planning the treatment to the patients.

Keywords: Oral submucous fibrosis, Serum copper, Serum zinc.

World Journal of Dentistry (2020): 10.5005/jp-journals-10015-1773
\end{abstract}

\section{INTRODUCTION}

Oral submucous fibrosis (OSMF) is a chronic progressive oral potentially malignant disorder (OPMD), which originates from lining of the oral cavity, soft palate and extends further to involve upper part of aerodigestive tract. ${ }^{1}$ This disorder was first reported by Schwartz in the year 1952 labeled as, "atrophia idiopathica (tropica) mucosae oris". ${ }^{2}$ According to the definition given by Pindborg, OSMF is, "an insidious, chronic disease affecting any part of the oral cavity and sometimes the pharynx. Although occasionally preceded by and/or associated with vesicle formation, it is always associated with juxta-epithelial inflammatory reaction followed by fibroelastic change of the lamina propria, with epithelial atrophy leading to stiffness of the oral mucosa and causing trismus and inability to eat". ${ }^{3,4}$ Sushruta, an eminent Indian physician termed this condition as "Vidari". ${ }^{5}$ This condition is widespread in the Indian subcontinent, Bangladesh, Sri Lanka, Taiwan, and Southeast Asia; however, few cases are also reported in Kenya, Europe UK, China, North America, Saudi Arabia. ${ }^{6,7}$ The clinical features include a progressive reduction in mouth opening, blanching of the oral mucosal lining that may be localized, diffused, or reticular giving a marble-line appearance, appearance of thick fibrous bands, ulcerations, burning sensation, loss of pigmentation of the oral mucosa, leathery texture, and depapillation of tongue. ${ }^{8,9}$ Other symptoms include dryness of mouth, blisters on mucosa especially in palate region, and altered gustatory sensations. ${ }^{10,11}$

Estimation of elements like copper (Cu), zinc ( $\mathrm{Zn})$, and iron (Fe) and their role in the pathogenesis of OSMF have been evaluated in various studies. These trace elements play an important role as biological and chemical markers in OSMF, in fact the Cu to $\mathrm{Zn}$ ratio is
${ }^{1,2}$ Department of Oral Pathology and Microbiology, Sharad Pawar Dental College, Datta Meghe Institute of Medical Sciences, Wardha, Maharashtra, India

${ }^{3}$ Research and Development Department, Datta Meghe Institute of Medical Sciences, Wardha, Maharashtra, India

${ }^{4}$ Department of Dental Surgery, Indira Gandhi Government Medical College, Nagpur, Maharashtra, India

${ }^{5}$ Department of Public Health Dentistry, Sharad Pawar Dental College, Datta Meghe Institute of Medical Sciences, Wardha, Maharashtra, India

Corresponding Author: Akhilesh G Agrawal, Research and Development Department, Datta Meghe Institute of Medical Sciences, Wardha, Maharashtra, India, Phone: +91 9890986206, e-mail: agrawalakhilesh77@gmail.com

How to cite this article: Hande A, Bansod AV, Agrawal AG, et al. Estimation of Serum Copper and Zinc in Patients of Oral Submucous Fibrosis in Rural Population. World J Dent 2020;11(6):478-481.

Source of support: Intramural Grant DMIMS

Conflict of interest: None

regarded as the most valid biomarker for OSMF. ${ }^{12}$ Several disorders like OSMF and other OPMDs have demonstrated alterations in the levels of these trace elements in either serum or plasma. The areca nut, one of the prime etiological factors for OSMF contains a high amount of $\mathrm{Cu}$ and it releases $\mathrm{Cu}$ in the oral cavity within 5-20 minutes of chewing it. High Cu release upregulates the lysyl oxidase enzyme, which causes maturation of excess collagen fibers leading to the formation of collagen bundles. ${ }^{13}$ Zinc is pivotal for immune 
cell functioning and it also plays an important role in wound healing, antioxidant defense, cell division, skin and muscle growth, etc. ${ }^{14}$ Estimation of $\mathrm{Cu}$ and $\mathrm{Zn}$ can be used as an adjuvant test either to clinical diagnosis or to other biochemical examinations, which are performed in patients with OSMF. Thus, variations in the concentrations of $\mathrm{Cu}$ and $\mathrm{Zn}$ in the serum of patients with premalignant disorders not only will help in arrival at diagnosis but also in treatment planning. It can also be used as a prognostic indicator. With this premise in mind, the present study was designed to estimate the level of $\mathrm{Cu}$ and $\mathrm{Zn}$ in the sera of OSMF patients.

\section{Materials and Methods}

The present study pursued permission from the Institutional Ethics Committee (IEC/2018-19/7124). Seventy participants clinically diagnosed with OSMF were included in group I and 30 age and gender-matched healthy participants were included in group II of the present study. Informed consent was obtained from each patient before sample collection.

\section{Inclusion Criteria for Group I}

Clinically diagnosed patients with positive signs and symptoms of OSMF who gave a positive history of deleterious habit like areca nut chewing, tobacco chewing, etc., reduced mouth opening and burning sensations in oral mucosa were included in the study and no histopathological evaluation was performed of the clinically diagnosed confirmed cases.

\section{Exclusion Criteria for Group I}

Patients with any systemic diseases or undergoing treatment for OSMF, pregnant woman, history of drug intake were excluded from this study.

\section{Criteria for the Control Group II}

(1) The participants giving his/her written consent to participate in the study. (2) Systemically healthy individuals; the participants without habit history. (3) No previous history of OSMF or other oral potentially malignant lesions. (4) The age of the participants selected as controls in the present study ranged from 17 to 59 years corresponding to the age range of OSMF cases.

Complete clinical examination was recorded on the casehistory template. The categorization of OSMF patients was performed based on the clinical presentation. These include the inability to endure hot and spicy food beverages, blanching of the oral mucous membrane, palpable fibrotic bands, which leads to further inability in mouth opening. ${ }^{15}$ The amount of association of oral mucous membrane and maximum inter-incisor opening was recorded. In group I, the study participants were further separated into subgroup group IA, group IB, group IC, and group ID depending on their OSMF disease stage. The clinical staging of OSMF was executed as per criteria prescribed by Lai et al., "16 "stage I: when the opening of mouth more than $35 \mathrm{~mm}$; stage II: in-between 30 and $35 \mathrm{~mm}$; stage III: if in-between 20 and $30 \mathrm{~mm}$ and stage IV: if it is less than $20 \mathrm{~mm}$ ".

\section{Sample Collection}

Under all aseptic condition and patient precaution, $3 \mathrm{~mL}$ of venous blood was drawn by venepuncture of median cubital vein and was collected in the plane bulb. It was kept for 40 minutes at room temperature and then the bulb was centrifuged at 3,000 rpm for 8 minutes to separate the serum. Serum, which was superficial after centrifugation process, was collected in another plane bulb and the samples were preserved at $-40^{\circ} \mathrm{C}$ in a frozen state until use.

\section{Estimation of $\mathrm{Cu}$ and $\mathrm{Zn}$}

The stored serum samples were brought to room temperature and serum $\mathrm{Cu}$ and $\mathrm{Zn}$ level was estimated by a calorimetric test using Dibromo-PAESA method described in the kit manufactured by Centronic $\mathrm{GmbH}$.

The results were analyzed using the Statistical Package of Social Science (SPSS, V 16.0 IBM Inc., USA). The statistical analysis was performed by applying the analysis of variance (ANOVA) test.

\section{Results}

In the present study, the patient's ages were in the range of 17-59 years with an average of $32.45 \pm 9.16$. There was male predisposition with a male:female ratio of 2.88 (Table 1 and Fig. 1). Most of the reported patients belonged to group IA $(30 ; 42.85 \%)$ followed by group IB $(25 ; 35.71 \%)$, and group IC $(15 ; 21.42 \%)$ and no cases were in stage IV OSMF which was group ID. A significant increase in the serum Cu levels was observed in all the stages of OSMF with a mean of $195.305 \mu \mathrm{g} / \mathrm{dL}$ when compared with the control group (mean = 139.79). Group II and group III participants showed higher levels of Cu than group I participants (Table 2). A significant decrease in the serum level of $\mathrm{Zn}$ with a mean of $80.12 \mu \mathrm{g} / \mathrm{dL}$ was noted than the control group $($ mean $=98.89)$ (Table 3$)$.

\section{Discussion}

Oral submucous fibrosis is a well-distinguished complex, irreversible highly potent OPMD. About 7-43\% of cases of OSMF have reported with epithelial dysplasia in various studies. However, malignant potential has been observed in $7-12 \%$ of cases of OSMF. ${ }^{17}$ Early diagnosis of such OPMD can help the clinicians to prevent it from transforming into malignancy. Therefore, a comprehensive study was carried out to evaluate the level of Cu and $\mathrm{Zn}$ in the sera of OSMF

Table 1: Gender distribution

\begin{tabular}{lll}
\hline Sex & Control & Cases \\
\hline Male & 20 & 52 \\
Female & 10 & 18 \\
\hline
\end{tabular}

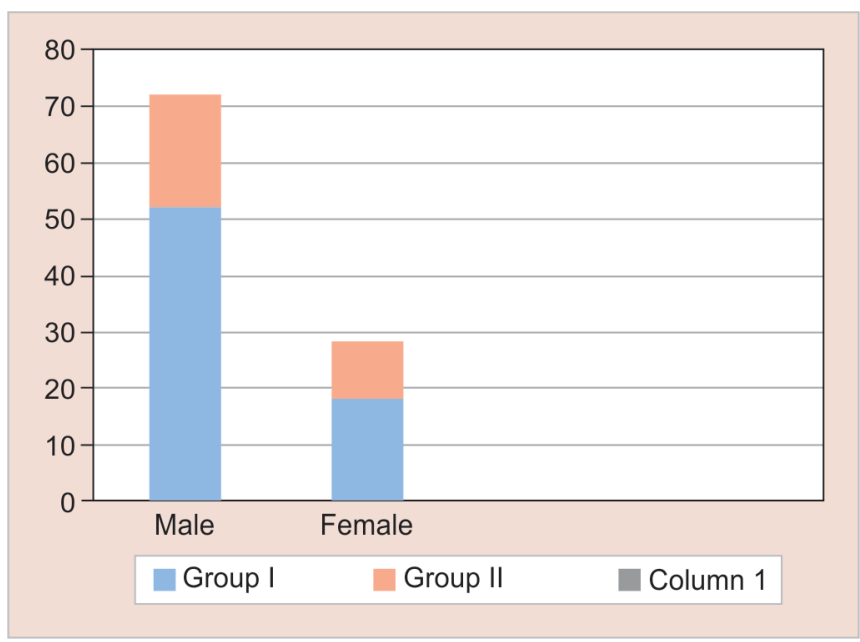

Fig. 1: Gender distribution in control and oral submucous fibrosis cases 
Estimation of Copper and Zinc in Oral Submucous Fibrosis Patient Contributors

Table 2: Comparison of mean serum level of $\mathrm{Cu}$ in controls and oral submucous fibrosis patients

\begin{tabular}{llllllll}
\hline Variable & $N$ & Minimum & Maximum & Mean & Std. deviation & $F$ & pvalue \\
\hline Group IA & 25 & 129.89 & 205.89 & 167.9172 & 22.83614 & 45.643 & $<0.001$ \\
Group IB & 25 & 136.55 & 236.45 & 198.7692 & 20.70612 & & \\
Group IC & 25 & 163.23 & 289.01 & 222.9352 & 39.25566 & \\
Group II (con- & 25 & 125.45 & 150.36 & 139.7856 & 5.21686 & & \\
trols) & & & & & & \\
\hline
\end{tabular}

Table 3: Comparison of mean serum level of $\mathrm{Zn}$ in controls and oral submucous fibrosis patients

\begin{tabular}{lllcrrrr}
\hline Variable & $N$ & Minimum & Maximum & Mean & Std. deviation & $F$ & $p$ value \\
\hline Group IA & 25 & 70.55 & 95.14 & 81.8552 & 5.77553 & 52.106 & $<0.001$ \\
Group IB & 25 & 58.78 & 82.65 & 75.3552 & 6.05806 & & \\
Group IC & 25 & 39.78 & 90.25 & 68.0572 & 12.37438 & \\
Group II (con- & 25 & 85.69 & 135.77 & 101.1613 & 13.65036 & & \\
trols) & & & & & & &
\end{tabular}

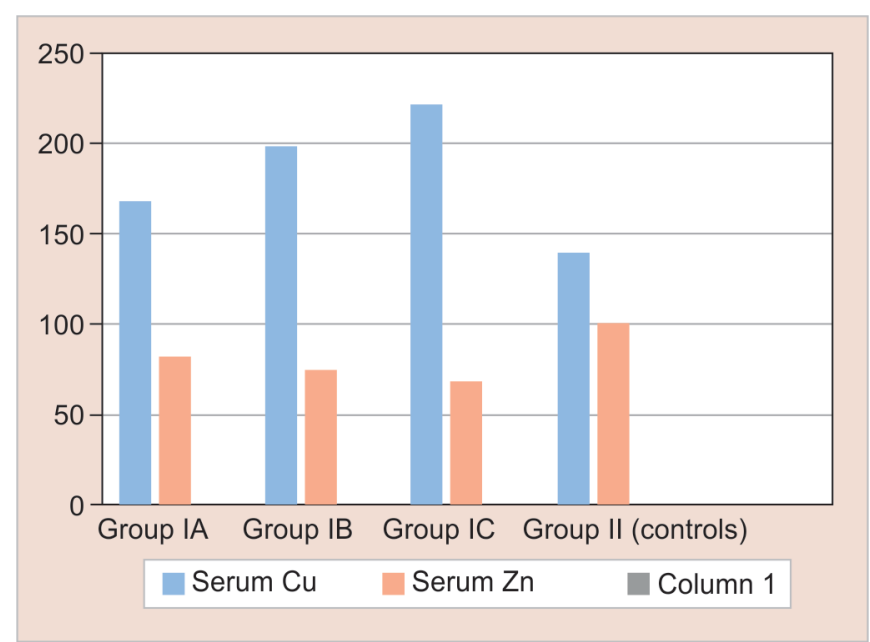

Fig. 2: Comparisons of trace elements in controls and grades of oral submucous fibrosis

patients in rural population. During the pathogenesis of OSMF, there are alterations in the level of such trace elements. The normal serum Cu level is, "20-70 g/dL in infants, 80-190 g/dL children, $04 \pm 21 \mu \mathrm{g} /$ $\mathrm{dL}$ in female and $103 \pm 23 \mu \mathrm{g} / \mathrm{dL}$ in male ${ }^{\prime 18,19}$ The normal range for $\mathrm{Zn}$ is, " $71-105 \mu \mathrm{g} / \mathrm{dL}$ in female and $72-106 \mu \mathrm{g} / \mathrm{dL}$ in male". ${ }^{18}$ Copper is an essential trace element engaged in activities of several mammalian enzymes. ${ }^{20}$ It plays an important role in erythropoiesis, collagen synthesis, and assists in iron absorption. In addition, it is part of many enzymes, such as, ceruloplasmin, cytochrome $c$ oxidase, and lysyl oxidase. ${ }^{21,22}$ Zinc, another important trace element, is mandatory for the enzymes required in DNA and protein synthesis and also proteins, lipids, carbohydrates, and lipid metabolism. ${ }^{23}$ Along with $\mathrm{Cu}, \mathrm{Zn}$ causes upregulation of superoxide dismutase (SOD) enzyme that leads to suppression of oxygen radicals. ${ }^{14}$ It is observed that levels of $\mathrm{Cu}$ and $\mathrm{Zn}$ in the sera of patients with OPMD (e.g., OSMF) and malignant (oral cancer) conditions are increased and decreased, respectively. ${ }^{24-26}$ In the present study, the mean age of the patients was 32.45 years (age range $=17-59$ years) which was in aligned with the study by Latoo and Nazir (age range $=17-60$ years) ${ }^{27}$ and Kumar et al. (age range $=24-58$ years) ${ }^{6}$ In contrast to this, $\mathrm{Khan}^{28}$ observed patients of age ranged from 14 to 44 years. We observed a male predilection for OSMF in the study, which is
74.2\%. A similar trend was observed by Yadav et al. ${ }^{26}$ (73\%), Nayak et al. ${ }^{29}(95 \%)$, etc. ${ }^{30,31}$ This study observed a significant increase in the serum Cu levels in all the three stages of OSMF with an upper limit of $446.09 \mu \mathrm{g} / \mathrm{dL}$. Similarly, Kode and Karjodkar, ${ }^{32}$ Shetty et al., ${ }^{25}$ and Yadav et al. ${ }^{26}$ observed increased serum Cu levels in OSMF patients. This significant increase in the Cu levels of OSMF patients could be attributed to the areca nut chewing habit that contains a large amount of $\mathrm{Cu}^{13}$ In OSMF patients, Trivedy et al. identified mutation of the $\mathrm{p} 53$ gene, which was induced by $\mathrm{Cu} .{ }^{33}$ Serum $\mathrm{Cu}$ levels were higher in stage II and stage III OSMF patients (i.e., group II and group III) when compared with stage I. This shows that as the severity of disease increases there is a corresponding increase in the Cu levels (Fig. 2). Our findings are in accordance with Tadakamadla and Kumar, ${ }^{34}$ and Khan. ${ }^{28}$

Zinc possesses anticancer property as it involved in various vital processes like DNA repair mechanism, transcription factor function, apoptosis inhibition, etc. ${ }^{7,35}$ Downregulation of $\mathrm{Zn}$ in the body has been strongly associated with cancers of breast, prostate, ovarian, oro-esophageal, and lung. ${ }^{36-40}$ The present study observed a significant decrease in serum $Z n$ level when compared with the control groups. The severity of this condition correlates with the $\mathrm{Zn}$ concentration as we found that grade I OSMF patient had higher serum $\mathrm{Zn}$ value than grade II and grade III patients (Fig. 2). These results were in consonance with the results of the studies performed by Yadav et al., ${ }^{26}$ Paul et al., ${ }^{41}$ and Nayak et al. ${ }^{29}$ However, some studies have reported higher concentration of $\mathrm{Zn}^{32,42}$ in the patients, which may be attributed to the high content of $\mathrm{Zn}$ in "gutkha" which is a mixture of tobacco, lime, and areca nut. The limitation of the study was that we did not assess any correlation of history of areca nut and tobacco chewing habit with the serum levels of $\mathrm{Cu}$ and $\mathrm{Zn}$.

\section{Conclusion}

There is an increased prevalence of OSMF in the rural population. Therefore, it is a prime requisite to diagnose the condition as early as possible to improve the health of the patients and prevent its malignant transformation. This study concludes that OSMF patients have notably increased levels of serum $\mathrm{Cu}$ and a definite reduction in serum $\mathrm{Zn}$ concentration. There is a direct proportionality of $\mathrm{Cu}$ levels and inverse proportionality with the severity of this condition. In lowsocioeconomic status population, supplements of Zn may improve the nutritional deficiency and prevent the patients from deleterious effects of $\mathrm{Cu}$. The study also concludes that serum $\mathrm{Cu}$ 
and $\mathrm{Zn}$ levels can be used as a valid biomarker for early diagnosis of OSMF. Furthermore, the level of Cu and $\mathrm{Zn}$ may assist in evaluating the severity of condition and guide in deciding the treatment strategy for a particle patient.

\section{References}

1. Wollina $U$, Verma SB, Ali FM, et al. Oral submucous fibrosis: an update. Clin Cosmet Investig Dermatol 2015;8:193-204.

2. Prabhu SR. Oral diseases in the tropics. Oxford, New York: Oxford University Press; 1992.

3. Pindborg JJ, Sirsat SM. Oral submucous fibrosis. Oral Surg Oral Med Oral Pathol 1966:22(6):764-779.

4. Tekade SA, Chaudhary MS, Tekade SS, et al. Early stage oral submucous fibrosis is characterized by increased vascularity as opposed to advanced stages. J Clin Diagn Res 2017;11(5):ZC92-ZC96.

5. Gowda BBK, Yathish TR, Sinhasan Sankappa P, et al. The response of oral submucous fibrosis to lycopene - a carotenoid antioxidant, A Clinicopathological Study. Journal of Clinical and Diagnostic Research 2011;5(4):882-888.

6. Kumar $\mathrm{H}$, Kumar $\mathrm{P}$, Jain $\mathrm{S}$, et al. Analysis of serum copper and iron levels in oral submucous fibrosis patients: a case-control study. Indian J Dent Sci 2016;8(3):145-149.

7. Sachdev PK, Freeland-Graves J, Beretvas SN, et al. Zinc, copper, and iron in oral submucous fibrosis: a meta-analysis. Int J Dent 2018;2018:3472087.

8. Yadav S, Verma A, Sachdeva A, et al. Etiopathogenesis and management of oral submucous fibrosis. Internet J Bioengineer 2010;5(1).

9. Hande AH, Chaudhary MS, Gawande MN, et al. Oral submucous fibrosis: an enigmatic morpho-insight. J Cancer Res Ther 2019;15(3):463-469.

10. Ali FM, Patil A, Patil K, et al. Oral submucous fibrosis and its dermatological relation. Indian Dermatol Online J 2014;5(3):260-265.

11. Rajendran R. Oral submucous fibrosis: etiology, pathogenesis, and future research. Bull World Health Organ 1994;72(6):985-996.

12. Srilekha M. Copper and zinc level in oral submucosal fibrosis (OSMF) patients. J Pharm Sci Res 2015;7(8):573-574.

13. Trivedy C, Warnakulasuriya KA, Hazarey VK, et al. The upregulation of lysyl oxidase in oral submucous fibrosis and squamous cell carcinoma. J Oral Pathol Med 1999;28(6):246-251.

14. Prasad AS. Zinc is an antioxidant and anti-inflammatory agent: its role in human health. Front Nutr 2014;1:14.

15. Pindborg JJ, Murti PR, Bhonsle RB, et al. Oral submucous fibrosis as a precancerous condition. Scand J Dent Res 1984;92(3):224-229.

16. Lai DR, Chen HR, Lin LM, et al. Clinical evaluation of different treatment methods for oral submucous fibrosis. A 10-year experience with 150 cases. J Oral Pathol Med 1995;24(9):402-406.

17. Hande AH, Chaudhary MS, Gadbail AR, et al. Role of hypoxia in malignant transformation of oral submucous fibrosis. J Datta Meghe Instit Med Sci Univer 2018;13(1):38-43.

18. Lin CN, Wilson A, Church BB, et al. Pediatric reference intervals for serum copper and zinc. Clin Chim Acta 2012;413(5-6):612-615.

19. Siddiqui I, Farooqui JQ, ShariffDA, et al. Serum copper levels in various diseases: a local experience at aga khan university hospital, Karachi. Int J Pathol 2006;4(2):101-104.

20. de Romaña DL, Olivares M, Uauy R, et al. Risks and benefits of copper in light of new insights of copper homeostasis. J Trace Elem Med Biol 2011;25(1):3-13.

21. Angelova $M$, Asenova $S$, Nedkova $V$, et al. Copper in the human organism. Trakia J Sci 2011;9(1):88-98.
22. Turnlund JR, Keyes WR, Anderson HL, et al. Copper absorption and retention in young men at three levels of dietary copper by use of the stable isotope 65Cu. Am J Clin Nutr 1989;49(5):870-878.

23. Prasad AS. Impact of the discovery of human zinc deficiency on health. J Am Coll Nutr 2009;28(3):257-265.

24. Khanna SS, Karjodkar FR. Circulating immune complexes and trace elements (copper, iron and selenium) as markers in oral precancer and cancer: a randomised, controlled clinical trial. Head Face Med 2006;2:33.

25. Shetty SR, Babu S, Kumari S, et al. Role of serum trace elements in oral precancer and oral cancer - a biochemical study. J Cancer Res Treat 2013;1(1):1-3.

26. Yadav A, Kumar L, Misra N, et al. Estimation of serum zinc, copper, and iron in the patients of oral submucous fibrosis. Natl J Maxillofac Surg 2015;6(2):190-193.

27. Latoo S, Nazir H. Estimation of levels of copper and iron in different stages of OSMF patients. Ann Int Med Den Res 2017;3(5):06-08.

28. Khan H. Evaluation of serum copper (cu), serum iron (fe) and serum copper (cu)/iron (fe) ration in oral submucous fibrosis in Karachi. J Adv Med Med Res 2018;26(6):1-9.

29. Nayak AG, Chatra L, Shenai KP. Analysis of copper and zinc levels in the mucosal tissue and serum of oral submucous fibrosis patients. Patil S, ed. World J Dent 2010;1(2):75-78.

30. Ranganathan K, Devi MU, Joshua E, et al. Oral submucous fibrosis: a case-control study in Chennai, South India. J Oral Pathol Med 2004;33(5):274-277.

31. Sinor PN, Gupta PC, Murti PR, et al. A case-control study of oral submucous fibrosis with special reference to the etiologic role of areca nut. J Oral Pathol Med 1990;19(2):94-98.

32. Kode MA, Karjodkar FR. Estimation of the serum and the salivary trace elements in OSMF patients. J Clin Diagn Res 2013;7(6):1215-1218.

33. Trivedy C, Meghji S, Warnakulasuriya KA, et al. Copper stimulates human oral fibroblasts in vitro: a role in the pathogenesis of oral submucous fibrosis. J Oral Pathol Med 2001;30(8):465-470.

34. Tadakamadla J, Kumar S, Mamatha GP. Evaluation of serum copper and iron levels among oral submucous fibrosis patients. Med Oral Patol Oral Cir Bucal 2011;16(7):e870-e873.

35. Pan Z, Choi S, Ouadid-Ahidouch $\mathrm{H}$, et al. Zinc transporters and dysregulated channels in cancers. Front Biosci (Landmark Ed) 2017;22:623-643.

36. Alam S, Kelleher SL. Cellular mechanisms of zinc dysregulation: a perspective on zinc homeostasis as an etiological factor in the development and progression of breast cancer. Nutrients 2012;4(8):875-903.

37. Christudoss P, Selvakumar R, Fleming JJ, et al. Zinc status of patients with benign prostatic hyperplasia and prostate carcinoma. Indian J Urol 2011;27(1):14-18.

38. Fan $Q$, Cai Q, Li P, et al. The novel ZIP4 regulation and its role in ovarian cancer. Oncotarget 2017;8(52):90090-90107. DOI: 10.18632/ oncotarget.21435.

39. Barch DH. Esophageal cancer and microelements. J Am Coll Nutr 1989;8(2):99-107.

40. Issell BF, MacFadyen BV, Gum ET, et al. Serum zinc levels in lung cancer patients. Cancer 1981;47(7):1845-1848.

41. Paul RR, Chatterjee J, Das AK, et al. Zinc and iron as bioindicators of precancerous nature of oral submucous fibrosis. Biol Trace Elem Res 1996;54(3):213-230.

42. Ayinampudi BK, Narsimhan M. Salivary copper and zinc levels in oral pre-malignant and malignant lesions. J Oral Maxillofac Pathol 2012;16(2):178-182. 